\title{
Leadership Development through Design Based Wilderness Education
}

\author{
http://dx.doi.org/10.3991/ijep.v5i1.4386 \\ C.R. Saulnier, B. Ahn, A. Bagiati, and J.G. Brisson \\ Massachusetts Institute of Technology, Cambridge, USA
}

\begin{abstract}
The Massachusetts Institute of Technology (MIT) has been collaborating since 2010 with the Singapore Ministry of Education to help develop the Singapore University of Technology and Design (SUTD). One element of this collaboration, the Global Leadership Program (GLP), aims to provide SUTD students with the opportunity to interact with the MIT community and experience MIT's academic culture. During GLP students participate in a program designed to develop leadership ability while also increasing their understanding of engineering science and design thinking. This paper introduces a curriculum implemented in the summer of 2014, that combines the pedagogies of design-based learning and wilderness education, to holistically address the development of these three competencies. Through design-based learning activities, both for and in a natural environment, students were encouraged to develop competency in engineering science and engineering design while exploring the diverse attributes essential for success as an engineer. This paper examines the results of a retrospective post-then-pre survey administered to participants upon completion of the program to explore the effects of the program on the development of professional engineering competencies. We find a statistically significant increase in items associated with Individual Leadership Skill, Group Leadership Skill and the role of Society and the Economy. These results are triangulated with student exit interviews and instructor observations.
\end{abstract}

Index Terms-Wilderness Education; Design-based Learning; International Collaborations; Cross-cultural Learning

\section{INTRODUCTION}

The Massachusetts Institute of Technology (MIT) has been collaborating since 2010 with the Singapore University of Technology and Design (SUTD) to help develop the latter's curriculum and educational programs. This collaboration aims "to accomplish the development of a new engineering-oriented university that will reach the Engineer of 2020 vision, while in parallel addressing the timely formation of an institutional identity and culture that borrows from those of MIT" [1]. Through this collaboration, MIT is involved in faculty training, the development and deployment of curricula, and supporting student life related initiatives such as the development of co-curricular and leadership activities [1]-[4].

While working on the development of student life, the MIT-SUTD Collaboration Office ran the first Global Leadership Program (GLP) in the summer of 2013. GLP brings between 25 and 30 SUTD students to MIT for ten weeks during the summer semester and provides SUTD students with the opportunity to interact with the MIT community and experience MIT's academic culture. During GLP, students participate in a program that assists in the development of engineering science and engineering design competencies alongside professional competencies. This program exists broadly in the context of a series of activities designed to encourage academic cultural transference between MIT and SUTD.

This paper introduces a component of GLP that combines the pedagogical approaches of design-based learning and wilderness education to create a novel learning environment for engineering students. This curriculum, designed with the multifaceted nature of the MIT-SUTD collaboration in mind, was first implemented in June to August of 2014. The design-based wilderness education curriculum begins with classroom and lab activities that are implemented on the MIT campus, followed by a wilderness education experience, a 3-day backpacking expedition in the White Mountain National Forest of New Hampshire.

Wilderness (and adventure) education programs aim to create a supportive environment in which students learn through the experience of challenge and adventure, relying on "the lessons available from the direct experience of nature and extended wilderness expeditioning" [5]. As we will explore, wilderness education curricula are typically focused on developing leadership and teamwork competencies, wilderness skills, and the personal character development of participants [5], [6]. Despite the fact that some of the skills and attributes developed through wilderness education map well to the skills and attributes desired in engineering education, design-based learning taking advantage of a wilderness environment appears to be a novel approach to engineering education. We have been unable to find other authors discussing the use of wilderness education to teach engineering competencies within the associated literature.

The application of design-thinking to generate physical artifacts is one of the fundamental distinctions of engineering as a profession. As described by Dym et al. in [7], emulating real-world engineering projects in the classroom "has recently turned out to be a major innovation in design pedagogy." These Project-Based Learning (PBL) experiences, often drawn from industry partners, "appear to improve retention, student satisfaction, diversity, and student learning" [7].

While design-based learning shares many of the characteristics of PBL, there are two important characteristics that distinguish our approach from many common implementations of PBL within engineering 
programs. As is typical, some design projects within the curriculum require teams of students to work together. However others require students to work individually, with the intention of supporting student self-reliance. The more pertinent distinguishing characteristic of designbased wilderness education is that students are expected to not just be the designers, but also the users, of their products. This is in contrast to most engineering design projects where students are following a process that is constructed to help them meet the needs of external clients or users.

After developing the theoretical justification for design-based wilderness-education as an appropriate curricular framework and describing the program as it was implemented, this paper examines the results of a retrospective post-then-pre survey administered to the participants using an instrument evaluating student selfperception of leadership characteristics related to engineering. These results provide an indication that, as expected, a curriculum blending wilderness education and design-based learning results in self-reported increases in student leadership capacity. Future work will examine the effects of this curriculum on student engineering and design related thinking and learning [8].

\section{PROGRAM JUSTIFICATION}

There are currently substantial efforts underway to reform engineering education and encourage global collaboration. In the United States, the introduction of the Engineering Criteria 2000 (EC2000) by the Accreditation Board for Engineering and Technology (ABET) required students in engineering programs to "learn to function on multidisciplinary teams", "communicate effectively", and "understand the impact of engineering solutions in a global, economic, environmental and social context" [9]. This trend towards outcome and competency based criteria targeting professional competencies is not limited to the United States. The 23 signatories of the Washington Accord, representing accreditation bodies from an array of countries in North America, Europe, Asia and Oceania, recognize the substantial equivalency of their individually accredited programs. Under this accord, a statement of graduate attributes and professional competency profiles requires engineering graduates be able to "assess societal, health, safety, legal and cultural issues", act "as a member or leader in diverse teams and in multi-disciplinary settings", and "communicate effectively on complex engineering activities with the engineering community and with society at large" [10].

Calling for a new kind of engineer in the United States, the National Academy of Engineering released a report entitled The Engineer of 2020: Visions of Engineering in the New Century, arguing that a broad range of skills should be inculcated into engineering graduates, including ingenuity, problem-solving capability, scientific insight, creativity, determination, leadership, conscience, vision, curiosity and wonder [11]. While strong analytical skills remained foundational, this report highlighted a complex world filled with social, environmental, political and economic considerations that would increasingly become a part of daily life for engineers. To help encourage success in this new context, engineering educators were challenged to engender creativity, communication, leadership, boldness, courage, dynamism, agility, resilience and flexibility in their students, attributes that would help engineering students meet the challenges of the modern world [11].

Despite efforts to implement curricula addressing the development of new skills and competencies, and the work of international collaborations, some indicators point to these efforts as being largely unsuccessful. Cech [12] found in a longitudinal survey of students at four US colleges (MIT, the Franklin Olin College of Engineering, Smith College, and the University of MassachusettsAmherst), that engineering education may foster a culture of disengagement, resulting in graduating students "less concerned with the importance of professional and ethical responsibilities, understanding the consequences of technology, understanding how people use machines, and social consciousness" than when they started their programs.

It is within the context of the aforementioned discussion that the design-based wilderness education curriculum was developed and implemented. We hope that this curriculum will add to the rich tapestry of methods through which future engineers around the world are prepared to meet global challenges.

While participating in design-based learning activities both for and in a natural environment, students will explore the diverse attributes essential for success as an engineer, while also relying on and developing skill in the practice of engineering science and engineering design. As the following sections explore, along with helping students transition to a new academic culture, wilderness education may be well suited as a learning environment for engineering education and fostering effective design-thinking practices in engineering students.

\section{A. Academic Culture Transition}

One of the primary purposes of GLP is to expose and transition participants from SUTD to the MIT academic culture. Wilderness Education is commonly used in North America in the context of introducing freshmen to the academic culture of college. There are indications that outdoor orientation programs are more effective at helping students transition into new academic cultures than more traditional orientation programs.

Almost 200 colleges in the United States and Canada use outdoor orientation programs to help students "develop a sense of belonging and status in transition", often resulting in long term measureable increases in factors such as retention rate and GPA [13]. These positive benefits, like others observed for wilderness education, have been attributed to a positive learning environment consisting of small and supportive peer groups. While there are some seemingly universal benefits, specific outcomes influenced by outdoor orientation programs depend partially on the focus of the curriculum [13]. This success of outdoor orientation programs to transition students into new academic cultures provides some indication that wilderness education may be a useful tool for achieving academic cultural transference as desired by GLP.

\section{B. Professional Development}

As discussed previously, many international outcome and competency based accreditation processes require students to act "as a member or leader in diverse teams 
and in multi-disciplinary settings" and "communicate effectively on complex engineering activities with the engineering community and with society at large" [10]. To help address these topics, many engineering programs include hybrid problem- and project-based learning approaches, most often in the form of capstone design projects, structured to allow students to work with industry partners on real world problems. This industry connection helps to contextualize the social and professional aspects of engineering, such as teamwork and communication [14].

Wilderness Education also has the potential to positively impact many of these professional engineering competencies in a lasting manner. Participants in wilderness education experiences typically express longterm increased competency in skills such as leadership, teamwork, self-confidence, and communication skills [15].

\section{Personal Development}

Wilderness Education programs have the potential to provide substantial and lasting outcomes regarding a student's perception of self, and changes in life perspective. In this environment, students can feel safe to explore their personal understanding and the relevance of many of the remarkable characteristics called for by the National Academy of Engineering, such as ingenuity, determination, curiosity and wonder. In the literature this potential is exemplified by a study interviewing participants 17-years after a 5-day wilderness orientation program. The participants consistently reported that the experience had helped them challenge assumptions of self and others, indicating that the program had provided "direction in their careers, direction in their personal lives, development of personal values and skills, and development of life-long friendships" [16].

Increased self-confidence and changes in life perspective are often reported in studies on wilderness education, and this effect is noticed even when not purposefully targeted by the curriculum [15]. As concluded in [15], "Wilderness education provides a unique social environment that allows participants to explore beliefs and assumptions that they hold, seemingly allowing for lasting changes in life perspective." A metaanalysis of 96 studies found that adventure programs have a greater effect on students' self-concept than traditional classroom-based interventions. Most strikingly, unlike other interventions it seems that "the effects of adventure programs continue to increase over time, and are maintained over considerable time" [17].

\section{Development of Design Thinking}

The previous two sections considered benefits that are traditionally associated with wilderness education that map directly to desired engineering education outcomes. Alongside these expected benefits, the design-based wilderness education environment has been specifically envisaged to help students develop competency in engineering science and engineering design.

The unique environment of the North American wilderness provides an opportunity for students to explore a problem-space with which they may be initially unfamiliar. This unfamiliarity is used to our advantage, with early lessons focusing on how basic scientific principles can be used to understand this seemingly new problem domain. Throughout the course students are encouraged to explain the world around them using basic scientific principles both relying on prior knowledge and through the exploration of new scientific concepts.

Design as a component of wilderness education results in a different set of incentives than traditional classroom experiences. As students are immediate users of their own design projects, often for the fulfillment of basic survival needs, students may be more intrinsically motivated to complete projects successfully. This is in contrast to a traditional design project in which students are designing for an external user. In many cases students may not expect their design to progress beyond an initial prototype or be used in any practical application other than for the awarding of a course grade.

\section{SitUATING THE CURRICULUM}

To better situate the curriculum in our unique context we will examine the expected characteristics of the students and the unique cross-cultural environment present during GLP. The design-based wilderness education curriculum was developed taking into account the context of the MIT-SUTD Collaboration and expectations regarding the students participating from SUTD. The inclusion of a wilderness education component was expected to be a somewhat novel learning environment for both the SUTD and MIT students alike. This novel learning environment was seen as a way to help level the playing field between the MIT and SUTD students, placing them in a learning environment with which they were all initially unfamiliar. By encouraging many students to step slightly outside of their comfort zone, students would have to learn to rely on each other and practice effective teamwork.

\section{A. Understanding the Learners}

The 2014 iteration of GLP had 30 participants from SUTD and 6 participants from MIT. It was expected that:

- The SUTD students attending GLP have already completed an intensive Introduction to Design course during their first year at SUTD.

- MIT's motto "Mens et Manus", Latin for "Mind and Hand", captures the hands-on academic culture that is found at MIT. While MIT students are expected to be familiar with a culture that values hands-on do-ityourself approaches to problem solving, this cultural attitude is not the norm in Singapore. SUTD is working to cultivate a hands on academic experience, and continuing to expose SUTD students to this culture is one of the primary goals of GLP.

- The North American environment is unfamiliar to the SUTD students. The flora, fauna, climate, terrain and remoteness of the expedition area all present new and unexpected challenges for the students. Singapore is a relatively flat island with very little area that could be considered wilderness, with consistently warm and humid weather. Conversely, New Hampshire has vast expanses of remote wilderness and a more temperate climate prone to large variations in temperature between day and night. 
- All male Singaporean citizens are conscripted for two years of National Service prior to entering university. Many of the students will therefore demonstrate strong pre-existing leadership and teamwork capability in physically and emotionally challenging environments.

While many of these assumptions proved to be correct, there were some surprises along the way that should be taken account for in future programs. While it was expected that the participants from MIT would be more familiar with the North American environment, it seemed that this advantage was not necessarily apparent when it came to the particulars of being in a backcountry environment. Some environmental factors did come as a surprise to the SUTD students, such as the temperature variation between day and night. More than one student would fall asleep outside of their sleeping bag, waking up freezing cold at some point during the night.

\section{B. Wilderness Education as a Cross-Cultural Experience}

Culture plays two important roles within the context of this curriculum. The instructors are instructing students from different cultural perspectives and backgrounds, while simultaneously attempting to inspire and encourage the SUTD students to transfer elements of MIT's academic culture back to SUTD. While the students have different cultural perspectives, wilderness education introduces an academic culture with which the students are likely to be unfamiliar.

Learning and teaching can be regarded as inherently cultural processes [18] and the academic culture of wilderness education will be novel to both the MIT and SUTD students. In the context of cross-cultural learning, successful out-of-school learning environments typically have scaffolding that consists of, "(1) organizing participation in activities in ways that address basic human needs for a sense of safety as well as belonging; (2) making the structure of the domain visible and socializing participants for dispositions and habits of mind necessary for expert-like practice; (3) helping novices understand possible trajectories for competence as well as the relevance of the domain to the learners; and (4) providing timely and flexible feedback" [18].

Wilderness educators recognize that wilderness experiences are a cross-cultural experience for most learners, no matter their cultural background. Mapping common wilderness education practices to this scaffolding, (1) conceptual models, such as Maslow's hierarchy of needs [19], are often used as a model to discuss physiological needs and security needs from the perspective of risk-management and creating an effective learning environment; (2) demonstrations, modeling, and coaching are all used to illustrate and encourage expertlike practice; (3) students are motivated by learning skills that are directly relevant to basic needs in their current living situation; (4) the natural environment is able to give direct and regular feedback to students, as there is no "need to contrive challenge, difficulty or especially risk" when students are engaged with the natural world [5].

\section{THE CURRICULUM}

The curriculum was originally developed using the Teaching for Understanding Framework which focuses on the development of generative topics, understanding goals, performances of understanding, and on-going feedback [20]. The wilderness education components of the curriculum are based on best practices from both Outward Bound [6] and the National Outdoor Leadership School [5]. With a curriculum that combines elements of design-based learning and wilderness education, students will be situated in an environment in which they will be able to experience conceptual changes in their understanding of the engineering profession and its role within an increasingly global society, while developing the skills and characteristics required to succeed in an increasingly modern interconnected world.

\section{A. Curriculum Design}

As a subcomponent of GLP, the prototypical designbased wilderness education program is focused around a classic wilderness education objective, a hiking expedition. A series of progressions take concepts from more traditional classroom settings to wilderness environments. These progressions are used to attempt to effectively develop further competency in the application of engineering science and design-thinking, while simultaneously developing engineering leadership competencies.

As outlined in Fig. 1, the design-based wilderness education curriculum as implemented consisted of four 3hour long sessions on campus over two weeks, followed by groups of 9 students and 2 instructors embarking on 3day backpacking expeditions over 4 weekends.

During the first class students were immediately prompted with the challenge of having to prepare for, and travel through, a true wilderness environment. Engaging with a learning environment that strips away much of the infrastructure and technology that has built up in society over time, students are better able to examine their personal relationship with technology and engineering. Through imagining, building and using artifacts of their own design to survive and thrive in the wilderness, it is hoped that students will continue to develop their competency in engineering science while directly

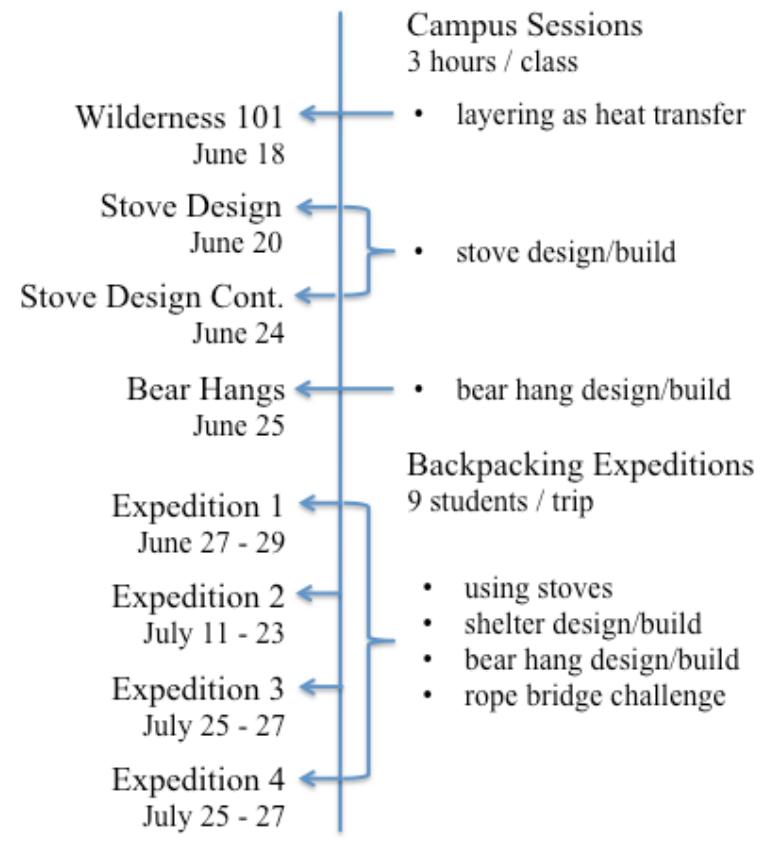

Figure 1. Timeline of design activities and challenges. 
experiencing the individual and social impacts that engineering artifacts produce. On an ongoing basis, students were encouraged to transfer this learning experience to their conceptualization of the engineering profession and its role within society.

To help students understand that this new and unfamiliar problem domain can be understood by applying basic engineering science principles, students were encouraged to consider clothing layering systems as a heat transfer problem. Considering heat loss and/or gain associated with convection, conduction, radiation and evaporative cooling alongside the properties of various fabrics commonly used in clothing, students are able to gain an understanding of appropriate clothing layering choices for the backcountry, a seemingly new understanding, from only the application of basic scientific principles. Students were encouraged to continue to apply this inquisitive and exploratory mindset through the rest of the course activities.

A series of progressions that begin with on-campus activities and progress to the wilderness environment provide students with the opportunity to engage in design-projects both individually and on teams. In the first progression, beginning in a classroom environment, students are provoked to consider what it means to design for a natural environment, developing a set of general design principles (such as durability, transportability, and reparability). Still on campus, students are challenged to design and build a prototype of a single burner alcohol stove. This design activity requires consideration of the physics of combustion, properties of the selected fuel, and the limitations of available materials. This design project follows students into the wilderness expedition as they are expected to use the stoves that they have designed and built to cook while camping. This use of their own design project, in the context of fulfilling a survival need, provided a very visceral context in which to consider the individual impact that engineering technology has on members of society.

Another progression challenges students to consider what it means to design in a natural environment. To begin to develop the skills necessary to use rope as a tool, students engaged in an activity on campus challenging them to build bear hangs (systems designed to elevate food above the ground in a forest such that bears and rodents cannot reach it). To do this students will have to understand and construct hauling systems using mechanical advantage, taking into account factors such as system extension under load, force on anchors, frictional force, and material breaking strength. Students then used this system while on the wilderness expedition, examining how the build process and design considerations changed when implementation is performed in an unknown natural wilderness environment. Further extending this concept, while on the backpacking expedition, students were challenged to design and construct a method to assist a person with a broken leg to cross a stream. To successfully construct the rope bridge students had to apply the skills learned during previous activities in novel ways.

Additionally, students slept under tarp shelters of their own design and construction while on the backpacking expedition. Using only plastic sheeting and string, students independently designed and constructed a shelter that they slept in for two nights. During initial construction students were encouraged to consider various design tradeoffs that may be apparent. After the first night students could choose to adjust their shelters based on their new experiences.

\section{METHODOLOGY}

Thirty SUTD and six MIT students were invited to participate in this study to evaluate the manner in which they transfer design processes to new environments and the potential effectiveness of a design-based wilderness education curriculum in developing engineering leadership and engineering science competencies. Table I describes the data that was collected during and after the curriculum implementation.

This paper explores the results of a survey on engineering leadership taken by the students after completing the curriculum. The administered survey was an inventory developed by Ahn et al. [21]. Specifically, the leadership survey assessed four separate factors of engineering leadership: Individual Leadership Skill, Group Leadership Skill, Society and Economy, and Development of an Adaptor to Change [21]. The Individual Leadership Skill (21 items) and Group Leadership Skill (8 items) factors are of particular interest as we expect that the traditional benefits of wilderness education would align closely with these factors. The third factor assessed consideration of the role of Society and Economy (12 items) on engineering as a profession. The remaining factor concerned with the Development of an Adaptor to Change contains four items and was not found to be as reliable as the other three factors contained within the instrument [21]. Thus, while the items in the Development of an Adaptor to Change factor were included on the survey for the sake of completeness, we do not analyze the results further in this paper. The 45item survey was administered online as a retrospective post-then-pre test to minimize response-shift bias and to effectively measure students' perception of change in their leadership abilities after the completion of the curriculum [22].

The survey results were triangulated with exit interviews and instructor observations. While a large amount of video was recorded, the footage available could not be effectively used to triangulate the results of this study on leadership and design-based wilderness education as the recordings were primarily explanations of individual design decisions and group synthesis activities.

TABLE I.

COLLECTED DATA

\begin{tabular}{|l|l|l|}
\hline \multicolumn{1}{|c|}{ Type of Data } & Students $(\boldsymbol{N}=\mathbf{3 6})$ & \multicolumn{1}{c|}{ Instructor } \\
\hline $\begin{array}{l}\text { Video of in-class design } \\
\text { and synthesis }\end{array}$ & $\begin{array}{l}\text { 1 hour of recordings from } \\
\text { 4 class sessions }\end{array}$ \\
\hline $\begin{array}{l}\text { Video of outdoor design } \\
\text { and synthesis }\end{array}$ & $\begin{array}{l}\text { 9 hours of recordings } \\
\text { from 4 expedition trips }\end{array}$ \\
\hline Reflective journals & 2 returned & $\begin{array}{l}\text { Handwritten notes and } \\
\text { approximately 100 } \\
\text { photos from class } \\
\text { sessions and expedition } \\
\text { trips }\end{array}$ \\
\hline Field notes and photos & 20 completed & \\
\hline Leadership survey & 34 participants & \\
\hline Exit interviews & & \\
\hline
\end{tabular}




\section{A. Data Collection}

All students were emailed a link to the survey four days after the last group had finished the backpacking expedition. Students were sent a reminder a week later. Twenty students (56\% response rate) voluntarily rated each item on a four-point Likert scale (1-Rarely, 2Sometimes, 3-Frequently, and 4-Almost Always). For the exit interviews, one member from the research team (who also instructed the program) interviewed 34 of the 36 student participants. The interview questions were openended and were asked within four days of the individual student completing the backpacking trip (the final element of the curriculum). The students were asked questions evaluating their perception of the strengths and weaknesses of the curriculum, what they learned, and how it could be improved. Each interview lasted approximately 15 minutes.

\section{B. Data Analysis}

Student survey results were analyzed on two levels: individual item and factor (i.e., group of items) levels. To examine the results on an individual item level, we calculated the 20 students' average pre- and post- scores for each item and calculated their differences. To examine the results on a factor level, we completed three paired-sample $t$-tests on the items that belong to Individual Leadership Skill (Factor 1), Group Leadership Skill (Factor 2) and Society and Economy (Factor 3) according to [21].

\section{LEADERSHIP SURVEY RESULTS}

Table II shows the pre- and post- survey results for each item belonging to the Individual Leadership Skill factor. The table presents items in descending order of difference, with the largest difference between pre- and post- score items listed first. The magnitude of the preand post- score differences ranged from 0.55 to 0.10 on a four-point scale. Larger differences indicate students reporting larger changes in behavior after completing the curriculum. As all the items in Table II show net increase in the difference, the course had a positive impact related to the skills associated with the Individual Leadership Skill factor.

One theme that can be noted from reviewing the items with large differences in Table II is students' willingness to take on (or accomplish) given tasks by actively engaging in positive leadership behavior. This theme is seen through items such as taking responsibilities (Item 1), sharing knowledge with others (Item 3), motivating peers to accomplish goals (Item 4), delegating tasks and sharing responsibilities (Item 5), stepping into a leadership position (Item 6), and establishing goals and sharing visions (Item 9). The theme was also highlighted during the exit interviews, where many students discussed the importance of knowing when to lead and when to step back and let others lead. Students discussed the importance of recognizing team members' skills, utilizing their expertise, sharing responsibilities, and trusting their team members to complete the assigned tasks. As one student said:

"I guess to identify the strengths in the group is very important...to get to know the people..."

Another observation from Table II is the number of items that had low pre- scores (i.e., equal to or below
2.30 on a four point scale) but had high post- scores. For example, clearly visualizing a project with limited information (Item 2), delegating projects and authority to others (Item 5), and solving problems in nontraditional ways (Item 7) were all initially rated equal to or below 2.30; however, after the course, they had some of the largest gains (a net gain of equal to 0.30 or above). These items with large differences indicate skills the students believed to have increased after the curriculum implementation.

There were, however, items with low pre- scores and with small differences after the curriculum implementation. These items included abilities to facilitate development opportunities for team members (Item 21) and to explain and discuss the fundamental elements of a project with others (Item 19). We believe

TABLE II.

ITEM SCORES FOR INDIVIDUAL LEADERSHIP SKILL

\begin{tabular}{|c|c|c|c|c|}
\hline$\#$ & $\begin{array}{l}\text { Individual Leadership Skill } \\
\text { Questions (Factor 1) }\end{array}$ & Pre & Post & Diff. \\
\hline 1 & $\begin{array}{l}\text { If I see the need, I take on } \\
\text { responsibilities that are not assigned to } \\
\text { me. }\end{array}$ & 2.40 & 2.95 & 0.55 \\
\hline 2 & $\begin{array}{l}\text { I clearly visualize a project even when I } \\
\text { am given limited information. }\end{array}$ & 2.25 & 2.70 & 0.45 \\
\hline 3 & $\begin{array}{l}\text { I look for opportunities to share my } \\
\text { knowledge with my peers. }\end{array}$ & 2.40 & 2.85 & 0.45 \\
\hline 4 & $\begin{array}{l}\text { I motivate my team members to } \\
\text { accomplish predefined goals. }\end{array}$ & 2.50 & 2.90 & 0.40 \\
\hline 5 & $\begin{array}{l}\text { I effectively delegate projects and } \\
\text { authority to other people. }\end{array}$ & 2.30 & 2.65 & 0.35 \\
\hline 6 & $\begin{array}{l}\text { I actively seek leadership opportunities } \\
\text { in and out of the classroom. }\end{array}$ & 2.40 & 2.75 & 0.35 \\
\hline 7 & $\begin{array}{l}\text { I am able to solve problems in } \\
\text { nontraditional ways. }\end{array}$ & 2.25 & 2.55 & 0.30 \\
\hline 8 & $\begin{array}{l}\text { Change is a smooth and easy process for } \\
\text { me. }\end{array}$ & 2.30 & 2.60 & 0.30 \\
\hline 9 & $\begin{array}{l}\text { I establish goals for a project and explain } \\
\text { the best way to accomplish these goals to } \\
\text { my team members. }\end{array}$ & 2.45 & 2.75 & 0.30 \\
\hline 10 & $\begin{array}{l}\text { I am not afraid to take risks when } \\
\text { making project-related decisions. }\end{array}$ & 2.50 & 2.80 & 0.30 \\
\hline 11 & $\begin{array}{l}\text { I clearly explain technical matters to } \\
\text { people who are not familiar with my area } \\
\text { of study. }\end{array}$ & 2.25 & 2.50 & 0.25 \\
\hline 12 & $\begin{array}{l}\text { I manage and organize my time } \\
\text { efficiently. }\end{array}$ & 2.35 & 2.60 & 0.25 \\
\hline 13 & $\begin{array}{l}\text { I can organize and structure a group to } \\
\text { accomplish a common goal. }\end{array}$ & 2.60 & 2.85 & 0.25 \\
\hline 14 & $\begin{array}{l}\text { I perceive myself to be technically } \\
\text { competent. }\end{array}$ & 2.20 & 2.40 & 0.25 \\
\hline 15 & $\begin{array}{l}\text { I independently initiate new individual or } \\
\text { team projects. }\end{array}$ & 2.30 & 2.50 & 0.20 \\
\hline 16 & $\begin{array}{l}\text { I take ownership of a project in which I } \\
\text { am involved. }\end{array}$ & 2.90 & 3.15 & 0.20 \\
\hline 17 & $\begin{array}{l}\text { I identify conflicts in a team project and } \\
\text { solve them before they harm the project } \\
\text { and the people involved. }\end{array}$ & 2.35 & 2.55 & 0.20 \\
\hline 18 & $\begin{array}{l}\text { I actively encourage my peers to solve } \\
\text { problems. }\end{array}$ & 2.40 & 2.60 & 0.20 \\
\hline 19 & $\begin{array}{l}\text { I easily explain and discuss the } \\
\text { fundamental elements of a project with } \\
\text { other team members. }\end{array}$ & 2.35 & 2.50 & 0.15 \\
\hline 20 & I am a confident person. & 2.50 & 2.65 & 0.15 \\
\hline 21 & $\begin{array}{l}\text { I facilitate developmental opportunities } \\
\text { for my team members during a project. }\end{array}$ & 2.30 & 2.40 & 0.10 \\
\hline
\end{tabular}


this result could be due to a lack of opportunity during some group activities for individual learning at a student's own pace. During the interviews, one of the female students highlighted this limitation. She referred to one class period where she wanted to learn independently how pulleys operated and how to tie ropes to design a bear hang. Due to a limited number of pulleys and ropes, as well as working with colleagues who arrived at a solution more quickly than she did because of their familiarity with the operation of pulleys and tying ropes, she did not have the time to learn and problem solve on her own. These survey and interview results suggest changes that could be made in future courses: for example, ensuring that there are sufficient resources for students to master course materials and allocating time for students to experiment on their own before or after working in groups.

Interestingly, even though students expressed increased positive leadership behaviors, students reported less change when asked if they considered themselves confident people (Item 20). This finding may be partially explained by students having a relatively high pre-score for this item, but it is worth noting that students may not have associated increased positive leadership behaviors with increased confidence.

The same item analysis used for Individual Leadership Skill was also conducted for the items associated with Group Leadership Skill. Table III presents the 20 students' averaged pre- and post- survey scores and their differences. The magnitudes of the differences ranged from 0.43 to 0.21 .

The common theme in Table III is students' ability to successfully collaborate. For example, working well with team members with different backgrounds (Item 2), taking into account opinions of all the people involved in the project (Item 3), gathering as much input as possible before making decisions (Item 4), and making team members feel important and getting them involved in a project (Item 5) all align with the theme of gathering input and working together with team members to find solutions.

The interview data also supported the survey results. During the interviews, students discussed the importance of letting others speak and listening to others' opinions. As one student stated:

"You must be willing to listen to what others have to say and then like be sure to talk about it."

When asked what lessons they were taking away from the experience, one student said:

"I think one aspect would be more open-minded because there's no one way of like doing stuff. And bouncing off ideas from friends. For example, I think that you can see from the river crossing [colleague name] and I had different ways of getting the rope tighter. His way was to do a double hitch and pulling it from the other side. So like halfway through I thought like oh he did not have enough rope to do that tightening through the butterfly knot but...and yet he did it and yeah, just trusting... So it's more like cooperation I guess, the value of cooperation is something that I will take away and getting ideas, trying to be more open."

Students recognized that fostering trust through authenticity and acting in accordance to one's values are important components of group leadership skills. Items
TABLE III.

ITEM SCORES FOR GROUP LEADERSHIP SKILL

\begin{tabular}{|c|c|c|c|c|}
\hline \# & Group Leadership Skill Questions (Factor 2) & Pre & Post & Diff. \\
\hline 1 & $\begin{array}{l}\text { I can acknowledge when I am wrong and learn } \\
\text { from my mistakes. }\end{array}$ & 2.68 & 3.11 & 0.43 \\
\hline 2 & $\begin{array}{l}\text { I work well with people who have backgrounds } \\
\text { that are different than my own. }\end{array}$ & 2.58 & 3.00 & 0.42 \\
\hline 3 & $\begin{array}{l}\text { When making decisions, I take into account } \\
\text { opinions of all the people involved in the } \\
\text { project. }\end{array}$ & 2.63 & 3.00 & 0.37 \\
\hline 4 & $\begin{array}{l}\text { I gather as much input as I can before making } \\
\text { decisions. }\end{array}$ & 2.63 & 3.00 & 0.37 \\
\hline 5 & $\begin{array}{l}\text { I do my best to make my team members feel } \\
\text { important and get involved in a project. }\end{array}$ & 2.63 & 3.00 & 0.37 \\
\hline 6 & I treat my peers with respect and dignity. & 3.26 & 3.53 & 0.27 \\
\hline 7 & $\begin{array}{l}\text { I create an environment of trust among my } \\
\text { team members. }\end{array}$ & 2.79 & 3.05 & 0.26 \\
\hline 8 & $\begin{array}{l}\text { I listen to my peers' concerns and opinions } \\
\text { even if they are different from my own. }\end{array}$ & 3.05 & 3.26 & 0.21 \\
\hline
\end{tabular}

TABLE IV.

ITEM SCORES FOR SOCIETY AND ECONOMY

\begin{tabular}{|c|l|c|c|c|}
\hline \# & Society and Economy Questions (Factor 3) & Pre & Post & Diff. \\
\hline 1 & $\begin{array}{l}\text { I pay attention to environmental issues while } \\
\text { designing new products. }\end{array}$ & 2.26 & 2.68 & 0.42 \\
\hline 2 & $\begin{array}{l}\text { I am primarily aware of cost and revenue when } \\
\text { designing a product. }\end{array}$ & 2.53 & 2.84 & 0.31 \\
\hline 3 & $\begin{array}{l}\text { I anticipate having to learn new skills over the } \\
\text { course of my career. }\end{array}$ & 3.25 & 3.55 & 0.30 \\
\hline 4 & $\begin{array}{l}\text { I consider my work as helping people to live } \\
\text { better lives. }\end{array}$ & 3.05 & 3.20 & 0.15 \\
\hline 5 & $\begin{array}{l}\text { I am aware of the impact that engineers have } \\
\text { on society. }\end{array}$ & 3.10 & 3.25 & 0.15 \\
\hline 6 & $\begin{array}{l}\text { I feel responsibility for the success and failure } \\
\text { of a project. }\end{array}$ & 3.21 & 3.32 & 0.11 \\
\hline 7 & $\begin{array}{l}\text { I understand the business implication of } \\
\text { product development. }\end{array}$ & 2.80 & 2.90 & 0.10 \\
\hline 8 & $\begin{array}{l}\text { I believe societal issues affect how engineers to } \\
\text { their jobs. }\end{array}$ & 2.95 & 3.05 & 0.10 \\
\hline 9 & $\begin{array}{l}\text { I believe that engineering design is affected by } \\
\text { issues related to social and business } \\
\text { environments. }\end{array}$ & 3.05 & 3.10 & 0.05 \\
\hline 10 & $\begin{array}{l}\text { I am aware of competition among companies in } \\
\text { my field. }\end{array}$ & 2.70 & 2.75 & 0.05 \\
\hline 11 & I am passionate about achieving my goals. & 3.21 & 3.21 & 0.00 \\
\hline 12 & $\begin{array}{l}\text { I believe that changes in the economy will } \\
\text { impact my job. }\end{array}$ & 3.10 & 3.05 & -0.05 \\
\hline
\end{tabular}

such as treating peers with respect and dignity (Item 6) and creating an environment of trust among team members (Item 7) showed moderate increases after the course.

The same analysis used for the first two factors was conducted for the items associated with Society and Economy. Table IV summarizes the gains before and after the design-based wilderness education course. The net average difference magnitudes ranged from a decrease of 0.05 to an increase of 0.42 .

The item with the largest change (Item 1) addresses the students' intention to pay attention to environmental issues when designing new products. While this was not an expressly stated goal of the program, simply living in a wilderness environment seemed to encourage an increased appreciation for the environmental impact of human activity. During the exit interview one student said: 
It makes me aware of a lot of other things such as caring for the environment specifically [...] we came near by a beaver dam and saw the beavers at night. We would wash our oily food and the ammonia or sulfur or whatever is in our soap may harm them. So when you have to walk like twenty meters up the hill just up to dig a hole and clean up that was when I realized okay - why what we do has an impact on others - just that we didn't take notice of it until you really go into the wilderness.

Interestingly, the second largest difference is for an item regarding cost and revenue awareness. On its face, this item is unrelated to the curriculum. One possible explanation is that students connected cost and revenue to their experience designing in and for a heavily resourceconstrained environment. This item warrants further investigation.

Many of the remaining items focus on social issues: the role of engineering to help people live better lives (Item 4) and to have an impact on society (Item 5) and the belief that societal issues affect how engineers do their jobs (Item 8). Even though these items were not a focus of the curriculum as implemented, a modest increase between pre- and post- scores is present.

Finally, descriptive statistic and paired sample $t$-test analyses were performed on the three factors. Descriptive statistic analysis was performed to obtain the factor scores, which are the sums of raw item scores loading on each factor. For example, for the Individual Leadership Skill factor with 21 items rated using a four-point scale, before the DBWE course, students' factor scores ranged from 32 to 64 with a mean of 49.26 . The results of the descriptive statistic analysis are presented in Table V.

The paired sample $t$-test analysis was conducted to determine whether there was a significant increase between the mean of the 20 students' factor scores before and after the DBWE course. Table VI summarizes the $t$ test results. For the Individual Leadership Skill factor, the result was significant, $t(18)=6.55, \mathrm{p}<.05, d=1.50$, indicating that there was a statistically significant increase in factor scores from before the course $(M=$ 49.26, $S D=9.42)$ to after the course $(M=55.47, S D=$ 8.38). Similarly the results for the Group Leadership Skill and Society and Economy factors were $t(18)=4.32, \mathrm{p}<$ $.05, d=0.99$ and $t(18)=4.53, \mathrm{p}<.05, d=1.04$, respectively, indicating a significant increase in mean factor scores from before to after the course. In addition, the effect sizes for all three factors were large based on Cohen's convention. These results indicate that the curriculum was effective in elevating students' individual and group leadership skills as well as their consideration of society and the economy as it relates to the profession of engineering.

TABLE V.

DESCRIPTIVE STATISTICS FOR INDIVIDUAL LEADERSHIP AND GROUP LEADERSHIP SKILLS, AND SOCIETY AND ECONOMY FACTORS

\begin{tabular}{|c|c|c|c|c|c|c|}
\hline $\begin{array}{c}\text { Factor } \\
\text { (\# of items) }\end{array}$ & Sums Scores & Min. & Max. & Mean (SD) & Median & Range \\
\hline \multirow{2}{*}{ Individual (21) } & Before & 32 & 64 & $49.26(9.42)$ & 51 & 32 \\
\hline & After & 43 & 70 & $55.47(8.38)$ & 54 & 27 \\
\hline \multirow{2}{*}{ Group (8) } & Before & 18 & 30 & $22.26(2.98)$ & 22 & 12 \\
\hline & After & 20 & 32 & $24.95(3.44)$ & 25 & 12 \\
\hline \multirow{2}{*}{$\begin{array}{l}\text { Society and } \\
\text { Economy (12) }\end{array}$} & Before & 27 & 45 & $35.05(5.33)$ & 35 & 18 \\
\hline & After & 29 & 47 & $36.68(5.06)$ & 35 & 18 \\
\hline
\end{tabular}

TABLE VI.

PAIRED SAMPle T-TeSt RESUlts For INDIVIDUAL AND GROUP LEADERSHIP SKILls, AND SOCIETY AND ECONOMY FACTORS

\begin{tabular}{|c|c|c|c|c|c|c|c|}
\hline \multirow{2}{*}{$\begin{array}{c}\text { Factor } \\
\text { (\# of items) }\end{array}$} & \multirow{2}{*}{$\begin{array}{l}\text { Avg. mean difference } \\
\text { (SD) }\end{array}$} & \multicolumn{2}{|c|}{ 95\% Confidence Interval } & \multirow{2}{*}{$t$} & \multirow{2}{*}{ df } & \multirow{2}{*}{$\begin{array}{c}\text { Sig. } \\
\text { (2-tailed) }\end{array}$} & \multirow{2}{*}{ Cohen's d } \\
\hline & & Lower & Upper & & & & \\
\hline Individual (21) & $6.21(4.13)$ & 4.22 & 8.20 & 6.55 & 18 & 0.00 & 1.50 \\
\hline Group (8) & $2.68(2.71)$ & 1.38 & 3.99 & 4.32 & 18 & 0.00 & 0.99 \\
\hline $\begin{array}{l}\text { Society and } \\
\text { Economy (12) }\end{array}$ & $1.63(1.57)$ & 0.87 & 2.39 & 4.53 & 18 & 0.00 & 1.04 \\
\hline
\end{tabular}

\section{DISCUSSION}

The design projects were designed for individuals and small groups to allow for a focus on individual selfreliance and resilience alongside teamwork. This was made with the knowledge that many of the students would enter the program with strong pre-existing leadership and teamwork competency. After participating in the course, students reported a significant increase in both individual and group leadership skill. As found in other studies, increases in individual and group leadership skills are an expected outcome of participating in wilderness education. However, it seems likely that the integration of design activities and the design-based framing of the curriculum further supported the development of engineering specific leadership traits.
As in other wilderness education settings, it was expected that students would report higher selfconfidence, however this was not the case. Students only reported a small increase when responding to the item, "I am a confident person." The difference of .15 is the second lowest increase within the 21 individual leadership skill items. While the technical complexity of the course was limited in scope, students reported a slightly larger increase of the item, "I perceive myself to be technically competent." This may be due to the design-based focus of the course inadvertently encouraging students to ascribe success to their skill as an engineer, rather than more global competencies. 
Students were for the most part able to successfully complete the intended design projects and it appeared that the practical design activities exposed incorrect conceptual models of physical phenomena that required students to develop more sophisticated understandings of concepts such as friction and combustion mechanics. In classroom observations indicated that participants were able to quickly synthesize new knowledge in an unfamiliar domain by applying an engineering science mindset to wilderness education problems, such as examining clothing layering and sleeping systems as a heat transfer problem.

Student enjoyment of the curriculum may have contributed to their perception of increased leadership ability. All of the interviewed students reported having an overall highly positive experience and that they would recommend the program to their friends. Even those who spoke of discomfort during the expedition and indicated a desire to never go camping again expressed this positive feeling and recommendation.

\section{FUTURE WORK}

As this study was exploratory in nature, we plan to continuously assess and evaluate the curriculum to ensure it has positive impact on student leadership development, understanding of engineering science, and design thinking.

For future studies, we plan to examine whether gain in student leadership skill is moderated by student gender, class standing, and/or past leadership experiences. Furthermore, as we will continue to have students participating from MIT and SUTD, we will examine whether there is a difference in the leadership skill development between these two student groups. These analyses will help determine whether the curriculum is biased towards certain student populations and will allow the instructor team to make necessary changes to ensure the course is effective and has a positive impact for all enrolled students.

Future work will also be focused on exploring the effect of the wilderness education curriculum on student engineering science and engineering design skillsets. A similar curriculum will be included in the 2015 iteration of GLP with a stronger focus on the design process. We are interested in more closely examining the role of the design process as, within the context of design-based learning, the design process provides structure and guidance as to how students should approach completing a design project. Beyond providing structure, the specific design process followed may have important effects on the learning outcomes and experience of the student. While most students are familiar with a point-to-point or iterative design process, the use of low-fidelity rapid prototyping or set-based-design may be more appropriate within the context of our pedagogy.

\section{LiMITATIONS}

The conclusions reached by this study are necessarily limited in scope as the students participating represent a very specific subset of the overall student population. GLP is a competitive program and it can be expected that the participants in this study have all demonstrated substantial prior academic and leadership capacity. While it is encouraging that this population of students reported positive benefits, follow-up study including a broader subset of the student population is warranted. The role that cross-cultural exchange plays in the success of this implementation of the curriculum is also unknown.

While the survey was performed anonymously online, the same member of the research team instructed the design-based wilderness education curriculum and performed the exit interviews. As was mentioned previously, a close and supportive small-group environment that promoted effective learning was developed during the wilderness expeditions. The personal relationship that students developed with the instructor may have biased some students to desire to report stronger positive outcomes from the program as it was being evaluated. One of the unique characteristics of wilderness education is that the effects tend to be lasting or even increase over time, a follow-up study could examine this effect while also providing an indication as to if the effects were initially overstated by students.

\section{CONClusions}

This paper focused on students' leadership development using interviews and survey data. Though we are still analyzing the video recordings, student journals, and field notes to assess the impact of the curriculum on the students' design-thinking and understanding of engineering science, our preliminary findings indicate that students understood the importance of keeping users and the environment in-mind when designing products as well as thinking outside the box and taking risks. Furthermore, students came to appreciate the non-linear design process from idea development to the manufacturing stage.

From the results of this study it appears that designbased wilderness education may be an appropriate pedagogy through which to target increased individual and group leadership skills. We believe that design-based wilderness education is uniquely positioned to positively impact students' leadership development while also influencing their understanding of engineering science and design thinking.

\section{ACKNOWLEDGMENT}

The authors would like to thank the MIT-SUTD Collaboration Headquarters office staff as well as the SUTD administration for supporting this work. The authors would also like to thank Tory Clark, Jesse DeLaughter, Kate Rhodes and Jacob Rosen for providing invaluable assistance as Instructors during the wilderness expeditions.

\section{REFERENCES}

[1] A. Bagiati, R. de Neufville, and S. Sarma, "Institutional Transplantation and Cultural Formation Through Faculty Development - A Yearlong Experience," in Proc. REES 2013 Symp., 2013.

[2] V. Sakhrani, A. Bagiati, S. Sarma, and R. de Neufville, "Institutional Transplantation in Education: Cultural Transfusion to a New Institution," in WEEF Int. Forum, 2012.

[3] A. Bagiati, D. Fisher, and S. Sarma, "Using Student Internship Programs as a Vehicle to International Campus Culture Transfusion," in WEEF Int. Forum, 2012.

[4] D. Fisher, A. Bagiati, and S. Sarma, "Student Ambassadors: Developing an Older Student Cohort," in Proc. 40th SEFI Conf., 2012. 
[5] J. Gookin, NOLS Wilderness Educator Notebook. Lander, WY: National Outdoor Leadership School, 2006.

[6] N. Crane, J. Frankel, K. Kager, J. Krebs, J. Kushner, A. Lodato, G. Ostherr, D. Owen, B. Roos, I. Perillo, D. Whyte, M. Lindsay, A. Ostreicher, J. Robertson, and M. B. Wyne, Outward Bound Staff Manual. Outward Bound U.S.A., 2008.

[7] C. L. Dym, A. M. Agogino, O. Eris, D. D. Frey, and L. J. Leifer, "Engineering Design Thinking, Teaching, and Learning," J. Eng. Educ., no. January, pp. 103-120, 2005.

[8] C. R. Saulnier, A. Bagiati, B. Ahn, and J. G. Brisson, "Changes in Student Design Thinking and Practice from Integrating Wilderness Education and Design Based Learning," Manuscr. Prep., 2014.

[9] J. W. Prados, G. D. Peterson, and L. R. Lattuca, "Quality assurance of engineering education through accreditation: The impact of Engineering Criteria 2000 and its global influence," $J$. Eng. Educ., vol. 94, no. 1, pp. 165-184, 2005. http://dx.doi.org/10.1002/j.2168-9830.2005.tb00836.x

[10] International Engineering Alliance, "Graduate Attributes and Professional Competencies.” pp. 1-16, 2013.

[11] National Academy Of Engineering, "The Engineer of 2020: Visions of Engineering in the New Century," pp. 53-37, 2005.

[12] E. A. Cech, "Culture of Disengagement in Engineering Education?," Sci. Technol. Human Values, vol. 39, no. 1, pp. 4272, Sep. 2013. http://dx.doi.org/10.1177/0162243913504305

[13] B. J. Bell, M. a. Gass, C. S. Nafziger, and J. D. Starbuck, "The State of Knowledge of Outdoor Orientation Programs: Current Practices, Research, and Theory," J. Exp. Educ., vol. 37, no. 1, pp. 31-45, Jan. 2014.

[14] J. Mills and D. Treagust, "Engineering education-Is problembased or project-based learning the answer?," Australas. J. Eng. Educ., vol. Online Pub, 2003.

[15] J. Sibthorp, N. Furman, K. Paisley, and J. Gookin, "Long-term Impacts Attributed to Participation in Adventure Education: Preliminary Findings from NOLS," in Research in Outdoor Education, 2008, vol. 9, pp. 86-103.

[16] M. A. Gass, D. E. Garvey, and D. A. Sugerman, "The Long-Term Effects of a First-Year Student Wilderness Orientation Program," J. Exp. Educ., vol. 26, no. 1, pp. 34-40, 2003.

[17] J. Hattie, H. W. Marsh, J. T. Neill, and G. E. Richards, "Adventure Education and Outward Bound: Out-of-Class Experiences That Make a Lasting Difference," Rev. Educ. Res., vol. 67, no. 1, pp. 43-48, 1997. http://dx.doi.org/10.3102/ 00346543067001043

[18] N. S. Nasir, A. S. Rosebery, B. Warren, and C. D. Lee, "Learning as a Cultural Process: Achieving Equity Through Diversity," in The Cambridge Handbook of the Learning Sciences, R. K.
Sawyer, Ed. New York, NY: Cambridge University Press, 2006, pp. 489-504.

[19] A. H. Maslow, "A Theory of Human Motivation," Psychol. Rev., vol. 50, no. 4, pp. 370-396, 1943. http://dx.doi.org/10.1037/ h0054346

[20] M. S. Wiske, "What Is Teaching for Understandng?," in Teaching for Understanding: Linking Research with Practice, Jossey-Bass, 1997, pp. 61-86.

[21] B. Ahn, M. F. Cox, J. London, O. Cekic, and J. Zhu, "Creating an Instrument to Measure Leadership, Change, and Synthesis in Engineering Undergraduates," J. Eng. Educ., vol. 103, no. 1, pp. 115-136, Jan. 2014. http://dx.doi.org/10.1002/jee.20036

[22] J. Sibthorp, K. Paisley, J. Gookin, and P. Ward, "Addressing Response-shift Bias: Retrospective Pretests in Recreation Research and Evaluation," J. Leis. Res., vol. 39, no. 2, pp. 295$315,2007$.

\section{AUTHORS}

C. R. Saulnier holds a degree in Computer Engineering and has instructed wilderness education programs with Outward Bound Canada. He is currently a Graduate Research Assistant with the MIT-SUTD Collaboration Office, Cambridge, MA 02139 USA (email: saulnier@mit.edu).

B. Ahn holds a $\mathrm{PhD}$ in the field of Engineering Education. He is currently a Postdoctoral Associate with the MIT-SUTD Collaboration Office, MIT, Cambridge, MA 02139 (e-mail: bahn@mit.edu).

A. Bagiati holds a $\mathrm{PhD}$ in the field of Engineering Education. She is currently a Research Scientist with the MIT Office of Digital Learning, and also the STEM Curriculum and Pedagogy Expert within the MIT-SUTD Collaboration Office, MIT, Cambridge, MA 02139 (email: abagiati@mit.edu).

J. G. Brisson is the director of the MIT-SUTD Collaboration Office and a Professor of Mechanical Engineering at MIT, Cambridge, MA 02139 (e-mail: brisson@mit.edu).

This article is an extended and modified version of a paper presented at the IEEE FIE conference held in Madrid, Spain, October 22-25, 2014. Submitted 15 January 2015. Published as resubmitted by the authors 14 February 2015. 